\title{
intyplow \\ OS INVISÍVEIS: Inclusão nos Anos Finais do Ensino Fundamental
}

\section{THE INVISIBLES: Inclusion in the Final Years of Elementary Education}

\author{
Rosimar Serena Siqueira \\ Programa de Pós-Graduação em Educação \\ da Universidade de Passo Fundo \\ ORCID: https://orcid.org/0000-0002-6918-2899 \\ E-mail: rosimaresquinsani@upf.br
}

\section{INTRODUÇÃO}

Ooutono de 1912, o escritor austro-húngaro Franz Kafka (1883 - 1924) Metamorfose. Publicada pela primeira vez em 1915, a obra narra a saga de Gregor Samsa, um caixeiro viajante que numa certa manhã, sem maiores explicações, acorda metamorfoseado num inseto (KAFKA, 2010). Após o impacto inicial, percebemos que Gregor apenas anseia continuar sendo visível. Todavia, as relações familiares e os contextos alteram-se substancialmente diante do 'novo' Gregor, retirado de uma cena familiar, laboral e social protagonista para o confinamento do seu quarto. Grassa a perspectiva do desconforto: seus parentes estão desconfortáveis em sua presença e esse sentimento somente é amenizado pela sua ausência física (recluso em seu quarto), até sua total invisibilidade.

O estranhamento de algo que nos era familiar mas que, inesperadamente, metamorfoseia-se em algo incompreensível parece ser uma analogia adequada para os anos finais do ensino fundamental (Fundamental II ou segunda fase do ensino fundamental). Tanto professores quanto alunos percebem-se, de um ano letivo para outro, convertidos em identidades que em outros tempos foram tão íntimas mas que, repentinamente, restam por estranhar-se: é o estranhamento da mudança de turno de aula; do revezamento de professores 
em diferentes disciplinas e, consequentemente, da perda da referência docente e, também, o estranhamento dos efeitos das condições particulares de desenvolvimento biológico, próprios da faixa etária.

Os alunos, que outrora eram os sujeitos de todas as atenções passam, abruptamente, a condição de ser somente mais um em meio a outros inúmeros uns... Os alunos já não são mais de ninguém, de nenhum professor em especial. Não há mais um pertencimento enfático. Não existe mais a turma da Fulana. Eles agora metamorfosearam-se em 'apenas' os alunos do 6o․ A, aprofundando o estranhamento...

E o desconforto da falta de compreensão para com as grandes e pequenas metamorfoses dessa etapa ganha contornos abissais quando a atividade-fim da escola precisa seguir o seu roteiro, como se a vida corresse normalmente... Assim como o Sr. Samsa, que se recusava a aceitar a metamorfose do filho e apenas seguia em frente, nós professores por vezes recusamos o enfrentamento do desconforto das mudanças típicas desta etapa de escolarização e, aparentemente, apenas seguimos em frente, preferencialmente sem ver, sem perceber as idiossincrasias entre o antes e o agora.

São as invisibilidades. O aluno dos anos finais do ensino fundamental em alguns contextos pode ser o 'invisível', aquele que está lá, como Gregor no seu quarto, mas que causa estranhamento e (talvez) repulsa. Melhor ficar lá, merecendo a atenção específica de poucos. E nesta lógica, há uma situação de escolarização nos anos finais do ensino fundamental ainda mais invisível: o aluno com deficiência, transtornos globais do desenvolvimento e altas habilidades ou superdotação. Em alguns contextos, este aluno pode ser o invisível entre os invisíveis.

O desconforto para com os alunos que são público alvo da educação especial (PAEE) nos anos finais assenta-se, em grande parte, pela complexidade inerente ao próprio processo de escolarização dos Anos Finais do Ensino Fundamental, potencializada pela presença do sujeito que exige um roteiro diferenciado, uma adaptação das relações e das práticas pedagógicas... melhor que ele seja, de fato, invisível (que Gregor fique trancado em seu quarto).

Falas como "No 7o. B tem 22 alunos e 03 incluídos"; "Dá um desenho pro Fulano pintar e não incomodar os demais, que farão avaliação"; "Eu não 
posso me prender ao planejamento para os dois incluídos, pois tenho mais 23 alunos na sala"; "O que eu faço com os normais, então?", ou ainda "Chama a colega da Sala de Recurso pra ficar com ele até os outros terminarem o exercício", apenas expressam o desconforto, o incômodo e a falta de entendimento que alguns professores tem acerca da inclusão, tanto em sentido amplo, quanto em relação ao PAEE, pois em geral "os profissionais da escola que atuam individualmente nas salas de aula não possuem respostas para a maior parte das dificuldades apresentadas pelos estudantes e não são capazes de realizar processos reais de ensino para alunos com deficiência quando trabalham individualmente" (VILARONGA; MENDES, 2014, p. 140).

Com base nestas e em outras percepções sobre tal 'invisibilidade', oriundas da prática pedagógica em escolas de educação básica, realizamos uma pesquisa analítico-reconstrutiva, pautada pelo procedimento da análise de conteúdo e referenciada na constituição de um corpus empírico formado por artigos de divulgação científica. A perspectiva que conduz o texto é evidenciar, de maneira palpável, se tal invisibilidade apresenta algum lastro de comprovação empírica, sinalizando se há, de fato, um silenciamento sobre a inclusão de alunos PAEE no ensino fundamental regular, com destaque para esta inclusão nos anos finais de tal etapa da educação básica.

Partimos da crença que uma...

educação que separa fisicamente os alunos é inerentemente discriminatória, desigual e, consequentemente, injusta. Por outro lado, a educação que meramente iguala, oferecendo o mesmo ensino no mesmo ambiente, também pode ser discriminatória, desigual e injusta se não responde às necessidades diferenciadas de alguns alunos. (MENDES, 2018, p. 80)

De tal modo, colocar os alunos em sala de aula mas torna-los 'invisíveis' em suas peculiaridades e idiossincrasias pode ser tão excludente quanto segrega-los, deliberadamente, em espaços específicos.

Por fim, cumpre informar que o texto apresentado é parte integrante de um contexto amplo de pesquisa, que objetiva contribuir para a discussão de políticas e mecanismos institucionais de gestão da educação em redes e sistemas públicos de ensino - incluindo processos e políticas de inclusão -, enquanto pauta importante na composição da agenda educacional. 


\section{DA METODOLOGIA E DO CORPUS EMPÍRICO...}

A pesquisa que deu origem ao texto em tela foi consubstanciada em uma metodologia analítico-reconstrutiva, pautada pelo procedimento da análise de conteúdo e amparada por breve revisão de literatura. Para o desenvolvimento dos argumentos, a pesquisa foi referenciada na composição de um corpus empírico estabelecido por artigos de divulgação científica, assumindo que tais artigos representam parte das pesquisas e produções sobre um determinado assunto/enfoque/área.

O procedimento metodológico adotado para exame dos artigos foi a análise de conteúdo, utilizando a técnica da análise temática, onde o "[...] tema é a unidade de significação que se liberta naturalmente de um texto analisado, segundo critérios relativos à teoria que serve de guia à leitura" (BARDIN, 2007, p. 105). Igualmente foram seguidos os passos descritos por Bardin (2007) como elementos de um procedimento de análise de conteúdo: 1) pré-análise (ou escolha e organização do corpus documental); 2) descrição analítica (investigação sobre o material); e 3) comentários ou glosas inferenciais.

O corpus documental foi constituído a partir do recorte de periódicos científicos avaliados por pares e publicizados no Portal de Periódicos da Coordenação de Aperfeiçoamento de Pessoal de Nível Superior / Capes (http:// www.periodicos.capes.gov.br/). A escolha pelo referido Portal reconhece a relevância do mesmo na ação de divulgação científica e, por conseguinte, de legitimidade dos discursos vinculados a partir daquele espaço. No Portal - de acesso livre - encontram-se, atualmente, mais de 45 mil títulos com texto completo, em 130 bases referenciais (http://www.periodicos.capes.gov.br/, capturado em 30 de abril de 2019).

Já a elegibilidade do recorte temporal - 2009-2018 -, constituiu-se em face a Política nacional de educação especial na perspectiva da educação inclusiva (BRASIL, 2008), considerando um hiato de implementação prática dos dispositivos da política, assim como um possível hiato na reação das pesquisas e consequentes produções acadêmicas acerca dessa política.

Procedimentalmente, realizamos uma busca simples no portal, operacionalizada através das expressões 'Educação Inclusiva' e 'Educação Especial'. Consideramos que, apensar dos termos eventualmente receberem condição de 
sinônimo, temos dois conceitos diferentes. A educação especial é compreendida como "uma modalidade de ensino que perpassa todos os níveis, etapas e modalidades, realiza o atendimento educacional especializado, disponibiliza os recursos e serviços e orienta quanto a sua utilização no processo de ensino e aprendizagem nas turmas comuns do ensino regular" (BRASIL, 2008).

Por seu turno, a educação inclusiva é mais abrangente, compondo...

uma ação política, cultural, social e pedagógica, desencadeada em defesa do direito de todos os alunos de estarem juntos, aprendendo e participando, sem nenhum tipo de discriminação. A educação inclusiva constitui um paradigma educacional fundamentado na concepção de direitos humanos, que conjuga igualdade e diferença com valores indissociáveis (BRASIL, 2008, p. 11)

Ante ao volume do retorno, foram realizadas três triagens: a primeira em relação ao período de publicação do artigo - retirando-se do computo geral todos os artigos que não correspondiam ao recorte temporal estabelecido entre 2009 e 2018; a segunda triagem em relação aos documentos, estipulando como filtro apenas artigos em português, e publicados em periódicos revisados por pares. Chegamos a um conjunto de 547 artigos em atenção aos refinamentos do termo 'Educação Inclusiva' e 867 artigos em atenção aos refinamentos do termo 'Educação Especial' distribuídos ao longo do período, de acordo com os registros das Tabelas 01 e 02.

Tabela 01 - Distribuição dos artigos sobre Educação Inclusiva por ano de publicação:

\begin{tabular}{cc}
\hline ANO DE PUBLICAÇÃO & QUANTIDADE DE ARTIGOS \\
\hline 2009 & 14 \\
\hline 2010 & 29 \\
\hline 2011 & 33 \\
\hline 2012 & 52 \\
\hline 2013 & 64 \\
\hline 2014 & 66 \\
\hline 2015 & 72 \\
\hline 2016 & 89 \\
\hline 2017 & 65 \\
\hline 2018 & 63 \\
\hline Total & $\mathbf{5 4 7}$ \\
\hline
\end{tabular}

Fonte: Organização da autora, 2019. 
Interessante perceber que há um tendencial e significativo aumento de produções que respondem ao termo de busca 'Educação Inclusiva' ao longo do período em recorte, com ênfase para o ano de 2016, que representa quantitativamente o pico de produções. Também é interessante observar que, mesmo que o conceito de educação inclusiva seja mais amplo do que educação especial, há um quantitativo significativamente maior de textos que respondem ao termo de busca 'Educação Especial', como demonstra a tabela a seguir.

Tabela 02 - Distribuição dos artigos sobre Educação Especial por ano de publicação:

\begin{tabular}{cc}
\hline ANO DE PUBLICAÇÃO & QUANTIDADE DE ARTIGOS \\
\hline 2009 & 32 \\
\hline 2010 & 42 \\
\hline 2011 & 60 \\
\hline 2012 & 83 \\
\hline 2013 & 68 \\
\hline 2014 & 109 \\
\hline 2015 & 123 \\
\hline 2016 & 105 \\
\hline 2017 & 134 \\
\hline 2018 & 111 \\
\hline Total & $\mathbf{8 6 7}$
\end{tabular}

Fonte: Organização da autora, 2019.

Novamente há um tendencial e significativo aumento de produções que respondem ao termo de busca 'Educação Especial' ao longo do período em recorte, com destaque para o ano de 2017, que representa quantitativamente o pico de produções acerca do termo.

A terceira triagem ocorreu de modo 'manual', revisando um a um os resumos dos artigos e mantendo, como corpus documental, apenas os artigos que efetivamente abordassem políticas e ações de educação inclusiva nos anos finais do ensino fundamental. Quando destacado apenas o conteúdo que aborda a educação especial em perspectiva inclusiva nos anos finais de escolarização, este número cai para 64 artigos. Estes 64 artigos restantes dedicam-se a temáticas como: financiamento da educação especial, atendimento em Sala de Recurso Multifuncional; formação inicial e ou continuada 
de professores para atuação nos anos finais do Ensino Fundamental; educação de jovens e adultos na fase do ensino fundamental II ou revisões de literatura.

Todavia, se examinados apenas os artigos que desenvolvem argumentos ou que focam no aluno PAEE que estuda nos anos finais do ensino fundamental, a quantidade de artigos reduz para 18. Ou seja, de um universo de 1.414 retornos, apenas 64 (ou 4,5\% do total) dedicam-se a tangenciar os processos inclusivos nos anos finais do ensino fundamental e, apenas 18 artigos (ou $1,2 \%$ dos retornos) focam tais processos de maneira central.

\section{DISCUTINDO OS DADOS}

Com relevância ampliada a partir dos últimos anos, o uso de periódicos como meios de divulgação científica tem se estendido pelas diferentes áreas do conhecimento humano e da produção acadêmica, autorizando a democratização (pelas facilidades de acesso, sobretudo em tempos de bibliotecas virtuais) de estudos e pesquisas. O discurso produzido pela pesquisa científica e indexado em periódicos consubstancia-se como um discurso de representação, um discurso referencial, de organização dos modelos e paradigmas da ciência ou dos pressupostos científicos em curso.

Assim, os temas e questões pontuadas em artigos de cunho científico revelam, em alguma medida, as tendências reconhecidas e os problemas emergentes na pesquisa científica, sendo que a presença ou não de um determinado tema ou enfoque pode indicar que tal questão ainda não recebeu (ou não merece?) atenção da comunidade científica.

No que diz respeito ao processo de inclusão do aluno público alvo da educação especial (PAEE) nos anos finais do ensino fundamental, parece existir uma invisibilidade do tema/abordagem nas pesquisas acadêmicas reverbe-

radas em artigos científicos. A timidez dos achados pode corroborar com a percepção empírica de tal timidez.

Quando aproximamos a lente de análise sobre os dezoito (18) artigos encontrados em um contingente de 1.414 artigos que mencionam 'educação especial' e/ou 'educação inclusiva', nos deparamos com quatro atributos: a) em sua totalidade, os artigos representam pesquisas qualitativas, exibindo estudos de caso de um ou poucos sujeitos (alunos, professores, escola); b) 
quinze (15) artigos tiveram como foco alunos, professores ou escolas da rede pública de ensino, um (01) da rede privada e dois (02) não evidenciam a rede de pertencimento dos sujeitos partícipes do estudo; c) cinco (05) artigos fazem interfaces com sujeitos cujo laudo aponta Deficiência Intelectual (CID 10 F70); dois (02) artigos indicam sujeitos com Autismo (CID 10 F84); um (01) artigo expõe investigações junto a sujeitos com Altas Habilidades/Superdotação (CID 10 F81), os demais artigos abordam a Educação Especial em perspectiva Inclusiva como movimento contemporâneo em redes e sistemas de ensino, sem apontar o estudo aproximado de sujeitos com laudos específicos; d) seis (06) apresentam o ponto de vista do professor, cinco (05) artigos apresentam o ponto de vista do aluno PAEE, quatro artigos (04) apresentam o ponto de vista de redes ou sistemas de ensino (com foco para experiências em escolas) e três (03) artigos apontam a visão dos pais sobre o movimento de escolarização regular dos seus filhos.

Os achados da pesquisa assentem, portanto, em duas reflexões preliminares: 1) parece haver, de fato, uma minguada produção intelectual representada em artigos de periódicos nacionais, no que diz respeito ao debate sobre o processo de escolarização dos alunos PAEE nos anos finais do ensino fundamental e, 2) apesar dos poucos artigos encontrados na garimpagem proposta, é possível realizar algumas inferências sobre os caminhos e possibilidades que a temática gesta. Tais inferências são detalhadas sequencialmente.

Em razão do primeiro atributo, ou o tipo de pesquisa utilizada, é lítico inferir que as pesquisas na área da educação especial em perspectiva inclusiva apontam para decisões e processos em aspecto qualitativo, informando o olhar apurado do pesquisador para casos singulares de uma realidade que também é singular e historicamente constituída. Assim, o trato com a pesquisa qualitativa também pode indicar que o tema é avesso a grandes tratamentos quantitativos e descrições generalistas, posto que cada criança e adolescente PAEE é sujeito de uma condição idiossincrática que exige uma leitura mais detalhada e aproximada por parte do pesquisador.

Apesar de minguadas, as pesquisas com alunos PAEE nos anos finais do ensino fundamental e em escolas regulares são, ao que indica o segundo atributo, desenvolvidas preferencialmente em escolas e redes públicas de ensino. O fato das escolas públicas serem as prioritárias no universo de pesquisas sobre o assunto referenda os dados de matrícula dos alunos especiais na educa- 
ção básica: das 1.181.276 matriculas na Educação Especial (classes comuns e/ ou exclusivas) em 2018, apenas 189.192 matrículas foram registradas na rede privada, ou seja, a rede privada é responsável por $16,01 \%$ do total de matrículas (dados da Sinopse Estatística da Educação Básica de 2018 - http://inep.gov. $\mathrm{br} /$ sinopses-estatisticas-da-educacao-basica, 2019). Disto resulta que a maior parte dos sujeitos PAEE está, de fato, na escola pública e é, portanto, sobre esta escola que a maioria dos pesquisadores se atem.

No que diz respeito ao terceiro atributo - ou as especificidades retratadas nos artigos -, as mesmas expressam em escala reduzidíssima (estamos falando de um conjunto de 18 artigos) as especificidades e laudos mais comuns em alunos PAEE. Em 2018 encontravam-se matriculados na Educação Básica, 801.727 alunos com diagnóstico de Deficiência Intelectual. Trata-se do diagnóstico mais corriqueira, visto que em sua sequencia figuram diagnósticos de Deficiência Física (145.083 alunos) e Autismo (119.608 alunos), como segunda e terceira especificidades mais comuns (dados da Sinopse Estatística da Educação Básica de 2018 - http://inep.gov.br/sinopses-estatisticas-da-educacao-basica, 2019).

Em relação ao quarto atributo - ou o ponto de vista dos artigos - sopesamos que quando o artigo está assentado na perspectiva do professor ou da escola, grassa o aspecto do fazer pedagógico, da receita, do procedimento, em uma evidente referência a um campo de ação e prática pedagógica que (ainda) está se constituindo. Os professores e escolas narram nos textos suas (des) venturas no processo de inclusão, mapeando contramarchas e tropeços, indicando caminhos e fazendo com que o texto seja, muitas vezes e por aparente necessidade, suficientemente prescritivo.

Todavia, quando o foco do artigo recai sobre o aluno PAEE e/ou sua família, a preocupação incide sobre seu ponto de vista, sua narrativa acerca dos processos que vivencia no interior do sistema escolar regular. Neste foco encontram abrigo narrativas de exclusão, incompreensão e abandono, reverberadas no fracasso e evasão escolar. Talvez por esta razão sejam tão minguados os estudos e pesquisas sobre o aluno PAEE nos anos finais do ensino fundamental: será que ele resiste a todo o processo de escolarização regular? 


\section{ALGUMAS REFLEXÕES SOBRE 0 ALUNO PAEE NOS ANOS FINAIS DO ENSINO FUNDAMENTAL}

Há alguns anos o Brasil exibe uma tendência de ampliação quantitativa, constante e progressiva de matrículas na Educação Básica, na modalidade de educação especial (art. 58 da LDB 9.394/1996), em grande medida impulsionada pela Política nacional de educação especial na perspectiva da educação inclusiva (BRASIL, 2008).

Do ponto de vista jurídico-normativo, o conceito de educação especial é definido pela Lei de Diretrizes e Bases da Educação Nacional nos seguintes termos "Art. 58. Entende-se por educação especial, para os efeitos desta Lei, a modalidade de educação escolar oferecida preferencialmente na rede regular de ensino, para educandos com deficiência, transtornos globais do desenvolvimento e altas habilidades ou superdotação" (BRASIL, 1996, com redação dada pela Lei no 12.796, de 2013).

Se verificados os Sinopses Estatísticas da Educação Básica de anos recentes, visualizamos a tendência progressiva de aumento da demanda, a partir da interpretação do crescimento anual do número de matrículas. Por exemplo, em 2007 o Brasil registrou 654.606 mil matrículas na Educação Básica, Modalidade Educação Especial. Em 2018 esse registro de matrículas já extrapolava um milhão, com 1.181.276 matrículas, um crescimento de mais de 50\%.

Tabela 03 - Matrículas na Educação Básica X Educação Especial - BRASIL

\begin{tabular}{cccc}
\hline & Total & Ed. Especial & \% \\
\hline $\mathbf{2 0 0 7}$ & 53.028 .928 & 654.606 & $\mathbf{1 , 2 3 \%}$ \\
\hline $\mathbf{2 0 0 8}$ & 53.232 .868 & 695.699 & $\mathbf{1 , 3 0 \%}$ \\
\hline $\mathbf{2 0 0 9}$ & 52.580 .452 & 639.718 & $\mathbf{1 , 2 1 \%}$ \\
\hline $\mathbf{2 0 1 0}$ & 51.549 .889 & 702.603 & $\mathbf{1 , 3 6 \%}$ \\
\hline $\mathbf{2 0 1 1}$ & 50.972 .619 & 752.305 & $\mathbf{1 , 4 7 \%}$ \\
\hline $\mathbf{2 0 1 2}$ & 50.345 .394 & 820.433 & $\mathbf{1 , 6 2 \%}$ \\
\hline $\mathbf{2 0 1 3}$ & 49.848 .027 & 843.342 & $\mathbf{1 , 6 9 \%}$ \\
\hline $\mathbf{2 0 1 4}$ & 49.771 .371 & 886.815 & $\mathbf{1 , 7 8 \%}$ \\
\hline $\mathbf{2 0 1 5}$ & 48.616 .812 & 930.683 & $\mathbf{1 , 9 1 \%}$ \\
\hline $\mathbf{2 0 1 6}$ & 48.642 .593 & 971.372 & $\mathbf{1 , 9 9 \%}$ \\
\hline $\mathbf{2 0 1 7}$ & 48.608 .093 & 1.066 .446 & $\mathbf{2 . 1 9 \%}$ \\
\hline $\mathbf{2 0 1 8}$ & 48.455 .867 & 1.181 .276 & $\mathbf{2 , 4 3 \%}$ \\
\hline
\end{tabular}

Fonte: Organização da autora, com base nas Sinopses Estatísticas da Educação Básica de 2007 a 2018 (http://inep.gov.br/sinopses-estatisticas-da-educacao-basica), 2019. 
A primeira linha da tabela, indica o número total de matrículas na educação básica brasileira, em série histórica. A segunda linha mostra, por sua vez, o número de matrículas na educação especial em classes regulares. Já a terceira linha da tabela 01 faz referência ao percentual de aumento das matrículas de alunos especiais em classes regulares, em comparação com a matrícula total de alunos.

Trata-se, sem dúvida, de um número considerável - e tendencialmente em ampliação -, de sujeitos que buscam, na educação básica, espaço para manifestação e desenvolvimento de suas condições específicas de aprendizagem, adicionando assim, o aumento do número de alunos Público Alvo da Educação Especial (PAEE) acolhidos nas escolas regulares - em atenção ao Art. 4으, inciso III da LDB 9.394/1996.

Pois quando tal universo em expansão se choca, por um lado com os processos de escolarização dos Anos Finais do Ensino Fundamental (Fundamental II ou segunda etapa do ensino fundamental) e, por outro, com um currículo recheado de proposições e engessamentos que indicam/pautam-se quase que exclusivamente pelo desempenho em avaliações em larga escala, temos uma equação que torna dos alunos PAEE, de fato, invisíveis.

\footnotetext{
Num certo sentido, a própria necessidade da criação de políticas de inclusão atesta a falta de uma cultura de inclusão. Fosse a educação ordinária inclusiva em si mesma, como, aliás, foi o espírito de seu início que data da democratização da escola abrindo suas portas para todas as crianças, não seria necessária a criação de políticas - extraordinárias - que não surgem senão de modo reparatório a essa tarefa ordinária que é realizada de modo insatisfatório. A grande aposta das políticas de inclusão é a de poder um dia deixarem de existir, após verem suas práticas transformadas numa cultura inclusiva (VOLTOLINI, 2019, p. 02).
}

Se tomarmos o conceito de inclusão como o "processo pelo qual a sociedade se adapta para poder incluir, em seus sistemas sociais gerais, pessoas com necessidades especiais e, simultaneamente estas se preparam para assumir seus papéis na sociedade" (SASSAKI, 1997, p. 41), podemos pontuar que o aluno PAEE merece experimentar tais papeis sociais desde a infância e adolescência, sendo protagonista de momentos/movimentos pedagógicos que passam, também, por um currículo adaptado às suas condições peculiares e, principalmente, pela visualização de suas necessidades por parte da escola e do professor. 
É mister lembrar que a escola pública concorre para cumprir uma missão humanitária, antes mesmo que pedagógica, condicionada a "minimizar o fracasso e combater todas as formas de fatalidade" (MEIRIEU, 2005, p. 75). Para cumprir esta missão, a escola pode movimentar-se no sentido de manter-se atenta, aberta e inclusiva. Atenta para todas as nuances e detalhes dos sujeitos que estão sob seu teto; aberta para a recepção das vicissitudes dos sujeitos que a ela acorrem (ainda que por diferentes razões), e inclusiva, para permitir que todos partilhem das mesmas informações, dos mesmos rituais e das mesmas práticas.

Tornar a escola inclusiva, integrativa e capaz de dar visibilidade aos 'invisíveis' não é uma opção, mas um compromisso ético e social, uma vez que:

Abrir a Escola para todos não é uma escolha entre outras: é a própria vocação dessa instituição, uma exigência consubstancial de sua existência, plenamente coerente com seu princípio fundamental [...]. A Escola, propriamente, é uma instituição aberta a todas as crianças, uma instituição que tem a preocupação de não descartar ninguém, de fazer com que se compartilhem os saberes que ela deve ensinar a todos. Sem nenhuma reserva (MEIREU, 2005, p. 44).

Ainda que os resultados escolares sejam relevantes e partícipes da estrutura administrativa de um sistema de ensino, "a qualidade de uma instituição não pode ser medida simplesmente pela satisfação de seus usuários, mas sim, pelos valores que deseja formar em seus alunos" (MEIRIEU, 2005, p. 144) e, dentre tais valores, ganha força o valor da inclusão e da (auto)aceitação para com as peculiaridades de cada um, em especial dos sujeitos PAEE.

Nesta direção,

A inclusão escolar, decorrente de uma educação acolhedora e para todos, necessita adotar a autonomia social e intelectual como objetivos norteadores da formação de educandos e de educadores, ao considerar que os caminhos pelos quais o conhecimento se produz não obedecem a critérios rígidos estabelecidos e limitados pelos componentes curriculares, mas, ao contrário, configuram redes imprescindíveis de ideias que se cruzam, formando tecidos singulares, sentidos originais. Esses movimentos colaboram para que os educadores se sintam capazes de trabalhar com todos os educandos, adequando suas práticas de acordo com o grupo heterogêneo de aprendizes presentes em sala de aula. (JESUS et al., 2012, p. 163).

A certeza de que a condição heterogênea de uma turma não ocorre apenas pela presença (?) de alunos PAEE, mas sim é uma qualidade inerente a 
qualquer sala de aula, configura-se como um horizonte de compreensão a ser perseguido, pois as pequenas e grandes invisibilidades cotidianas não atingem apenas alguns, senão todos os sujeitos que se implicam no processo. Parece lícito advogar que a inclusão - como conceito amplo - diz respeito a todos os sujeitos em processo de escolarização nos anos finais do ensino fundamental (centralidade da proposta em discussão), sendo que o aluno PAEE é, nesta conjuntura, o representante mais tempestivo do debate.

Por outro lado, a presença efetiva de alunos incluídos nos bancos escolares das escolas regulares requer mudanças nas estruturas até então vigentes. O que era óbvio passa a exigir

Mudanças essas que vão desde a ampliação arquitetônica, atitudinal e conceitual para as crianças com deficiência, transtornos globais do desenvolvimento e altas habilidades/superdotação nos contextos escolares, até a implantação de políticas públicas que visam à construção de práticas que permitam a efetiva participação desses alunos nos processos de ensino e de aprendizagem (DECHICHI, 2011, p. 7)

As estruturas escolares sobrevêm ao questionamento, inclusive as estruturas pedagógicas, pois não basta colocar o aluno para dentro da sala de aula, sem oferecer condições mínimas de aprendizagem e integração. Há alguns dispositivos jurídico-normativos que norteiam procedimentos materializáveis de inclusão e que passam, entre outras ações, pelas adaptações curriculares registradas no planejamento.

Nesta direção...

...a criação de uma cultura inclusiva não depende estritamente da criação de leis específicas, mas exige um tipo de engajamento de todos e da dialetização dos impasses e conflitos advindos desse engajamento na direção da construção de um novo tipo de laço social. Esse engajamento não pode ser apenas moral, ou seja, suportado em uma declaração de apoio à causa, mas ético, quer dizer, baseado em um exame de nossas próprias implicações no processo segregativo (VOLTOLINI, 2019, p. 02)

Cumpre, porém, salientar a necessária fuga dos raciocínios aligeirados e óbvios, que restam por culpabilizar o professor pela ausência de efetividade em práticas inclusivas (especialmente para os anos finais). Ele, em diversos contextos, não se sente preparado e apoiado para realizar uma ação pedagógica inclusiva. Se tratar das invisibilidades e estranhamentos do aluno 
dos Anos Finais já é substancialmente desafiador, tal desafio é potencializado quando se trata do aluno PAEE. Todavia, os movimentos de acesso a este professor e a sua prática pedagógica carecem de sistematizações e disciplina. De acordo com Figueiredo

\begin{abstract}
Alguns professores aderem rapidamente e demonstram confiança na possibilidade de desenvolverem uma pedagogia que contemple as diferenças de todos os alunos. Outros, ao contrário, resistem a essa ideia, e, há aqueles que se apropriam pouco a pouco dessa concepção e vão implementando pequenas mudanças no ensino e na gestão da classe (FIGUEIREDO, 2010, p. 37)
\end{abstract}

Assim, a escola exclui ou aceita e naturaliza a 'invisibilidade' do aluno, mas muitas vezes este movimento é involuntário... não exclui porque quer, mas porque não sabe, não tem apoio e fóruns adequados para o debate e a ação sobre o como incluir. Tal constatação empírica faz com que a formação dos sujeitos que se responsabilizam - em esferas públicas - pela inclusão (como os professores), seja condição basilar para um processo de inclusão mais efetivo, naturalizado e, por conseguinte, orgânico.

Seria tempestivo e oportuno ter como horizonte que "uma escola que exclui não é uma Escola: é uma oficina de formação, um clube de desenvolvimento pessoal, um curso de treinamento para passar em concursos, uma provedora de mão-de-obra ou uma colônia de férias reservada a uma elite social" (MEIREU, 2005, p. 44).

Mesmo ciente das limitações que se colocam diante de uma educação mais inclusiva e integrativa, parece admissível indicar que o silenciamento sobre alguns tópicos - como os anos finais do ensino fundamental, no espectro do presente texto -, não colabora em nada para uma educação, de fato, inclusiva. É preciso falar sobre o assunto, polemizar se necessário, mas dar visibilidade a sujeitos e processos no interior da escola. E que Gregor possa sair do seu quarto, interagir com a família e ouvir sua irmã tocando violino (KAFKA, 2010).

\title{
CONCLUSÃO
}

A pesquisa que originou o presente texto partiu de uma premissa constatada em experiências pessoais com escolas públicas: há uma invisibilidade 
que assola os alunos dos anos finais do ensino fundamental. Os mesmos são 'invisíveis' em suas peculiaridades etárias e na identidade traçada no interior da escola: eles, que até então eram os alunos do $4 \underline{0}$ ano da professora fulana, nos anos finais passam a ser apenas mais um número. Tal invisibilidade acomete também - e talvez, principalmente -, os alunos Público Alvo da Educação Especial quando os mesmos chegam aos anos finais do ensino fundamental.

Assim, o texto tomou para si o objetivo de evidenciar, de maneira palpável, se tal invisibilidade apresenta algum lastro de comprovação empírica, sinalizando se há, de fato, um silenciamento sobre a inclusão de alunos PAEE no ensino fundamental regular, com destaque para esta inclusão nos anos finais de tal etapa da educação básica.

Como lastro empírico foi escolhida a produção científica, indicando se artigos publicados em periódicos tem se dedicado ao tema, ou se mesmo na condição de objeto de estudos científicos, a escolarização regular do aluno PAEE é invisível.

A conclusão possível, retirada de um conjunto limitado a 1.414 artigos publicizados no portal de periódicos da CAPES -, indica que sim, a escolarização regular de alunos PAEE nos anos finais do ensino fundamental também é 'invisível' como preocupação acadêmica, uma vez que apenas 18 artigos mencionavam preocupações centrais com tal tema.

Entretanto, da tímida amostra de artigos que evidenciam tal temática como central, foi possível indicar quatro atributos que, tendencialmente, podem nortear a pesquisa acerca do tema: a) prioridade para pesquisas de cunho qualitativo; b) foco em pesquisa com alunos, professores ou escolas da rede pública de ensino, o que converge para os dados de matrícula dos alunos PAEE, em sua maioria matriculados em escolas públicas; c) os artigos abordam a Educação Especial em perspectiva Inclusiva como movimento contemporâneo em redes e sistemas de ensino, sem apontar o estudo aproximado de sujeitos com laudos específicos mas, quando o fazem, priorizam interfaces com sujeitos cujo laudo aponta Deficiência Intelectual (CID 10 F70), convergindo novamente para dados de matricula na educação básica, que apontam tal especificidade como a mais comum entre os alunos PAEE e, d) a maior parte dos artigos apontam para o ponto de vista do professor e das redes ou sistemas de ensino. 
Por fim, o texto indica algumas elaborações conceituais acerca da presença do aluno PAEE na escola regular, sobretudo nos anos finais do ensino fundamental, indicando a necessária ampliação de pesquisas na área como fator de colaboração para a reversão do quadro presente de 'invisibilidade' da temática.

\begin{abstract}
Resumo: O texto parte da premissa que há uma invisibilidade que assola os alunos dos anos finais do ensino fundamental. Os mesmos são 'invisíveis' em suas peculiaridades etárias e necessidades específicas. Tal invisibilidade acomete também alunos Público Alvo da Educação Especial quando os mesmos chegam aos anos finais do ensino fundamental. Assim, o texto objetiva evidenciar lastros de comprovação empírica acerca de tal invisibilidade, sinalizando o silenciamento sobre a inclusão de alunos PAEE no ensino fundamental regular, com destaque para os anos finais de tal etapa da educação básica. A pesquisa foi consubstanciada em uma metodologia analítico-reconstrutiva, pautada pelo procedimento da análise de conteúdo e amparada por breve revisão de literatura. Para o desenvolvimento dos argumentos, o procedimento metodológico adotado foi a análise de conteúdo, utilizando a técnica da análise temática, sendo que o corpus documental foi constituído a partir de artigos de periódicos científicos avaliados por pares e publicizados no Portal de Periódicos da Coordenação de Aperfeiçoamento de Pessoal de Nível Superior / Capes, entre 2009 e 2018. Conclui respondendo de forma positiva a premissa inicial: a escolarização regular de alunos PAEE nos anos finais do ensino fundamental também é 'invisível' como preocupação acadêmica, reverberada em publicações científicas.
\end{abstract}

Palavras-chave: inclusão; visibilidade; anos finais do ensino fundamental; publicações científicas.

\begin{abstract}
The text starts from the premise that there is an invisibility that plagues students in the final years of elementary school. They are 'invisible' in their age peculiarities and specific needs. This invisibility also affects students Target Audience Special Education when they reach the final years of elementary school. Thus, the objective of this text is to show evidence of empirical evidence about such invisibility, signaling the silencing of the inclusion of PAEE students in regular primary education, with emphasis on the final years of such stage of basic education. The research was based on an analytical-reconstructive methodology, guided by the content analysis procedure and supported by a brief literature review. For the development of the arguments, the methodological procedure adopted was the analysis of content, using the technique of thematic analysis, and the documentary corpus was constituted from articles of scientific journals evaluated by pairs and published in the Portal of Periodicals of the Coordination of Improvement of Higher Education Personnel / Capes between 2009 and 2018. It concludes by responding in a positive way to the initial premise: regular schooling of PAEE students in the final years of elementary education is also 'invisible' as an academic concern reverberated in scientific publications.
\end{abstract}

Keywords: inclusion; visibility; years of elementary school; Scientific publications.

\title{
REFERÊNCIAS BIBLIOGRÁFICAS
}

BARDIN, Laurence. Análise de Conteúdo. Trad. Luiz Antero Reto e Augusto Pinheiro. Lisboa: Edições 70, 2007.

BRASIL Secretaria de Educação Especial. Política Nacional de Educação Especial na Perspectiva da Educação Inclusiva. Brasília, DF, jan. 2008. [Documento elaborado pelo Grupo de Trabalho nomeado pela portaria n. 555/2007, prorrogada pela portaria n. 948/2007, entregue ao ministro da Educação em 7 de janeiro de 2008])

DECHICHI, Claúdia; SILVA, Lázara Cristina da; FERREIRA, Juliane Madureira (Org.). Educação especial e inclusão educacional: formação profissional e experiências em diferentes contextos. Uberlândia: EDUFU, 2011. 
HAAS, Clarissa; SILVA, Mayara Costa da; FERRARO, Alceu Ravanello. Escolarização das pessoas com deficiência no Rio Grande do Sul ante o direito à educação. Educação e Pesquisa, São Paulo, v. 43, n. 1, p. 245-262, mar. 2017.

JESUS, Denise Meyrelles de et al. As políticas públicas em ação no Estado do Espírito Santo: o que dizem as superintendências e as secretarias municipais de educação. In: MENDES, Eniceia Gonçalves; ALMEIDA, Maria Amelia (Org.). A pesquisa sobre inclusão escolar em suas múltiplas dimensões: teoria, política e formação. Maília: ABPEE, 2012. p. 159-174.

JESUS, Denise Meyrelles de; VIEIRA, Alexandro Braga; EFFGEN, Ariadna Pereira Siqueira. Pesquisa-ação colaborativo-crítica: em busca de uma epistemologia. Educação \& Realidade, Porto Alegre, v. 39, n. 3, p. 771-788, 2014.

KAFKA, Franz. A metamorfose. São Paulo: Conrad editora do Brasil, 2010.

MEIRIEU, Philippe. O Cotidiano da Escola e da Sala de Aula: o fazer e o compreender. (Faire l'école, faire la classe). Porto Alegre: Artmed, 2005.

MENDES, Enicéia Gonçalves. Sobre alunos "incluídos": reflexões sobre o conceito de inclusão escolar. In: VICTOR, Sonia Lopes; VIEIRA, Alexandro Braga; OLIVEIRA, Ivone Martins de (Org.). Educação especial inclusiva: conceituações, medicalização e políticas. Campos dos Goytacazes, RJ: Brasil Multicultural, 2018. p. 58- 81.

SILVA, Naiane Cristina; CARVALHO, Beatriz Girão Enes. Compreendendo o Processo de Inclusão Escolar no Brasil na Perspectiva dos Professores: uma Revisão Integrativa. Revista Brasileira de Educação Especial, Marília, v. 23, n. 2, p. 293-308, jun. 2017.

VIEIRA, Alexandro Braga; RAMOS, Ines de Oliveira; SIMOES, Renata Duarte. Inclusão de alunos com deficiência e transtornos globais do desenvolvimento: atravessamentos nos currículos escolares. Educação e Pesquisa, São Paulo, v. 44, e180213, 2018.

VILARONGA, C. A. R.; MENDES, E. G. Ensino colaborativo para o apoio à inclusão escolar: práticas colaborativas entre os professores. Revista Brasileira de Estudos Pedagógicos, Brasília, v. 95, n. 239, p. 139-151, jan./abr. 2014.

VOLTOLINI, Rinaldo. Interpelações Éticas à Educação Inclusiva. Educação \& Realidade, Porto Alegre, v. 44, n. 1, e84847, 2019.

Recebido em Outubro de 2020

Aprovado em Fevereiro de 2021 